\title{
Challenging Climate Strikers' Youthfulness: The Evolution of the Generational Gap in Environmental Attitudes Since 1999
}

\author{
Jasmine Lorenzini ${ }^{1 *}$, Gian-Andrea Monsch ${ }^{2}$ and Jan Rosset ${ }^{1}$ \\ ${ }^{1}$ Institute of Citizenship Studies, University of Geneva, Geneva, Switzerland, ${ }^{2}$ FORS, University of Lausanne, Lausanne, \\ Switzerland
}

In 2019, youth took to the street to express their fears and ambitions in relation to climate change. Alongside, many adult and senior citizens expressed their solidarity. While the media present environmental issues as being generationally dividing, we know little about potential differences between generations in terms of environmental attitudes. In this paper, we analyze data collected in the framework of street demonstrations in Switzerland and longitudinal data collected in the Swiss population. Our analyses of survey data on climate strike demonstrators in Switzerland show that while the early demonstrations

OPEN ACCESS

Edited by:

Matt Henn,

Nottingham Trent University,

United Kingdom

Reviewed by:

Carla Malafaia

University of Porto, Portugal Robert A. Huber,

University of Salzburg, Austria

*Correspondence:

Jasmine Lorenzini

jasmine.lorenzini@unige.ch

Specialty section:

This article was submitted to

Political Participation,

a section of the journal

Frontiers in Political Science

Received: 25 November 2020

Accepted: 15 April 2021

Published: 07 May 2021

Citation:

Lorenzini J, Monsch G-A and Rosset J (2021) Challenging Climate Strikers

Youthfulness: The Evolution of the

Generational Gap in Environmental

Attitudes Since 1999.

Front. Polit. Sci. 3:633563.

doi: 10.3389/fpos.2021.633563 attracted mostly youth, the age composition of climate strike demonstrators became more diverse over time increasingly including members of different generations. Furthermore, we explore how age differences evolved over the last 20 years using the Swiss Household Panel data. Our analyses show that the share of individuals who favor the environment over the economy is greater among younger generations and that the climate strike generation stands out with the largest share of pro-environmental attitudes. However, all generations have moved in parallel over the last twenty years following a non-linear but generally upward trend illustrating that the political context affects all generations. Overall, our analyses contribute to understanding incremental changes in public attitudes in the environmental area and the role played by generational renewal in these regards.

Keywords: environmental attitude, climate strikes, youth, age, generations

\section{INTRODUCTION}

In 2019, young people across European countries took to the streets to express their environmental concerns. In particular, school and university students organized numerous protest events during that year. In Switzerland, many of these protest events took the form of climate strikes organized in several cities across the country on at least 18 occasions since December 2018. This wave of protest characterized by regular strikes and demonstrations culminated with the demonstration that took place in Bern on September 28, 2019 which gathered around 100,000 protesters coming from the whole country. This demonstration was one of the most sizable protest events in Switzerland since the Second World War. In their reports, the media have put a strong emphasis on the youthfulness of participants in these events, calling participants Klimajugend ${ }^{1}$ or

${ }^{1}$ Which could be translated as youth for the climate (see e.g., SRF, the Swiss public television). 
describing the mobilization as being a youth movement. ${ }^{2}$ The media framed it as youth protest, thus, suggesting that the climate is a preoccupation mostly of young people.

While youth were instrumental in initiating the movement, we know little-beyond media reports-about the age distribution of participants in these demonstrations (apart from the two reports from the climate strike international team, see Wahlström et al., 2019; de Moor et al., 2020). It is likely that the characteristics of participants to these events evolved as demonstrations became larger over time. The demonstrations could draw from environmental activists who participated in previous waves of mobilization and/or from a broader audience of citizens sensitized to the environmental question in the last decades. Research shows that social movements durably shape the action repertoires of those who engage in protest during their formative years, individuals who came of age during the $60 \mathrm{~s}$ and 70 s remain the most active generation in the streets (Caren et al., 2011; Grasso, 2014; Giugni and Grasso, 2019). In addition, over time, social movements have broad cultural impacts and contribute to important shifts in public opinion (Amenta and Polletta, 2019). Social movements shape the political attitudes of those who engage in protest but more generally those of broad segments of the population (Rochon, 2000). In fact, research on public opinion shows relatively little polarization along generational lines about environmental issues (Kissau et al., 2012; Franzen and Vogl, 2013; Beiser-McGrath and Huber, 2018; Gray et al., 2019).

However, given the unprecedented nature of the climate strike movement, it is likely that these findings from previous studies no longer apply. In other words, the generational gap in proenvironmental attitudes might have widened over the last few years and that current youth generation displays different opinions on environmental issues as compared to other generations. After all, previous youth generations have not initiated environmental movements, so maybe there is something specific about the current youth generation. At least, this is the narrative expressed in the media, which characterized the demonstrations as youth events and insisted on generational differences on environmental issues. Given the lack of studies on the age composition of the climate strike movement and the absence of more recent analysis of the generational gaps in environmental attitudes that would include the current youth generation, we propose to study the following research questions. First, what is the composition in terms of generations of the climate strike demonstrations? Second, to what extent the generation who initiated the climate strike differs from other generations in terms of proenvironmental attitudes, today and when these older generations were young?

Answering these questions enables to characterize the current environmental movement in terms of generations engaged in the events they organize and to assess potential generational

\footnotetext{
${ }^{2}$ For instance, on March 15 2019, one of Le Temps headlines is: « Face à "l'urgence climatique," la jeunesse s'est emparée de la rue " (translation : "To call out the "climate urgency," youth has conquered the streets ").
}

cleavages around environmental issues in Switzerland by looking at levels of support for these issues across generations and how they evolve over time. Is the fact that youth initiated the movement linked to their biographical availability and propensity to protest? Or, does it reflect the fact that today's young generation has specific preferences that differ from previous generations? These questions speak to the literatures on social movements, as well as to the literature on public opinion. The literature on social movements puts emphasis on youth biographical availability (Wiltfang and McAdam, 1991; Corrigall-Brown, 2011) and highlights the continued protest potential of the social movement generation (Caren et al., 2011). Whereas, public opinion research tends to link age with specific interests associated with life cycles (Andor et al., 2018) or contextual factors (Gray et al., 2019) that shape the specific preferences of age groups.

The climate strike demonstrations offer an opportunity to analyze generational effects on participation in events associated with the environmental movement. We test these effects in a country where the environmental movement has organized many protest events during the last decades. Hence, in a context where the environmental movement contributed to shaping the action repertoires and environmental preferences of different generations. Switzerland represents an interesting case study for two reasons. First, the demonstrations related to the Friday for the Future movement have attracted very large numbers of demonstrators. In comparative perspective and relative to its population size, Switzerland is one of the countries with the highest rate of participation in these demonstrations. ${ }^{3}$ Second, it represents a case in which the environmental movement has a long history (see section 2 below) and in which this movement has been institutionalized already in the 1970s. ${ }^{4}$ Switzerland represents a case in which large differences across generations are less likely.

Our empirical analysis consists of two parts. First, we explore the generational composition of the climate strike demonstrations, in the early phase of the movement and 6 months later, to understand who the climate strike demonstrators are. Second, using longitudinal data, we examine how widespread is support for the environment across different generations in the Swiss population. Our results indicate that while climate strike demonstrations had a high proportion of youth in March 2019, a majority of the participants to the climate strike events in September were aged 35 years or more. Thus, they are not part of the climate strike generation. This shows the ability of the movement to bring large shares of the population to the streets, but also its mischaracterization by the media. The analysis of panel data shows that the climate strike generation holds more pro-

\footnotetext{
${ }^{3}$ According to the Fridays for the Future website, more than $1.5 \%$ of the Swiss population participated in demonstrations making it the third country with the highest participation rate in the world after Austria and Italy. For details see: https://fridaysforfuture.org/what-we-do/strike-statistics/map-percentage/.

${ }^{4}$ As an example of the success and institutionalisation of the environmental movement, one could mention that Switzerland was the first country in the world to elect a Green representative in a national election in 1979.
} 
environmental preferences than older generations do. However, the analysis also reveals that the change has been progressive with each generation being slightly more pro-environment than its predecessor is and that all generations moved in parallel over the last 10 years becoming significantly more pro-environment during that decade. Overall, those results show that there is no strong generational cleavage regarding environmental protection in Switzerland.

In the next section, we first review the literature that links age, generations, and political activism as well as environmental preferences. Building on existing research on youth social movement activism and political attitudes, we formulate two expectations related to youth participation in the climate strike and their environmental preferences compared to older citizens. In addition, we propose two accounts of changes over time in environmental attitudes. Next, we track environmental protest waves in Switzerland to identify environmental generations. Then, we present the data, our operationalization of key variables, and the methods that we use to compare generations and to track changes over time. Lastly, we present and discuss our findings and we conclude with a discussion of the limits of our paper as well as avenues for further research.

\section{Age, Activism, and Political Preferences}

Successful social movements span multiple generations and contribute to social change through different processes. In this paper, we first analyze the composition of climate strike demonstrations in terms of age to see which generations participate in these protest events. Here, we build on the literature on biographical availability (McAdam, 1986; Wiltfang and McAdam, 1991) and the effects of social movements on political socialization (Caren et al., 2011). In addition, we consider two alternative accounts of how social movements contribute to social change. These contrasting views are associated with the study of generational changes (Mannheim, 1970) and that of post-materialism (Inglehart, 1977).

The literature on youth political participation often studies youth political disengagement (Henn et al., 2002; Amnå and Ekman, 2014; Dahl et al., 2018). Research shows that young people tend to be less engaged than older citizens in institutional politics but they do participate in politics through other means (O'Toole, 2003; Earl et al., 2017). An extensive literature argues that youth are more likely to engage in social movements. It is commonly held that young activists, are more progressive than the rest of society (Milkman, 2017). However, what is more important is their biographical availability defined as "the absence of personal constraints that may increase the costs and risks of movement participation" (McAdam, 1986: 70). These personal constraints relate to family and employment situation. Those individuals who are not in a stable relationship and are still studying are deemed more "available" to engage in protest activities, namely that they have more time that could be dedicated to protest. In addition to biographical availability, Schussman and Soule (2005) examine political engagement and structural availability. Political engagement refers to political attitudes such as political interest and efficacy, while structural availability relates to participation in civil society organizations and other networks that promote political activism. In other words, young people are more likely to engage in political activism because they have the time, the interest, and the networks. This comes close to the famous civic voluntarism model which explains that people engage because they want to (political attitudes including openness and willingness to change society), they can (political resources including time), and because they have been asked (Verba et al., 1995).

This suggests that citizens protest when they are young and then refrain from political participation or turn to institutional politics. However, research shows that individuals who came of age in periods of intense political mobilization remain more active in protest politics throughout their lives (Caren et al., 2011; Grasso, 2014; Giugni and Grasso, 2019). These individuals form social movement generations who adopt specific action repertoires in which protest is more prominent. In addition, these early political experiences shape how they understand subsequent political events (Bartels and Jackman, 2014). Thus, lending support to Mannheim's theory of generational change. Young people who experience their formative years in a given historical and social period belong to a generation (Mannheim, 1970). A generation is a group of persons who come of age at the same time and share a lived experience of this historical period. Although individuals may hold different values depending on their socioeconomic standing and partisanship, this means that they share similar understandings of the world. Not all periods are equally likely to have a strong impact on youth. Intense periods of social change are more likely to have a durable impact on youth understanding and perception of the world around them, thus to influence their values and their behaviors (Rochon, 2000). Sometimes, these periods of social change are tied to protest waves, phases of heightened political conflict (Tarrow, 1989), during which protest events regularly take place. These movements question prevailing understandings of society and propose alternative models. These events contribute to young people's political socialization. Youth learn to see the world through specific lenses. Young people acquire political values as they discuss with their peers in periods of intense political mobilization, but also within the family. Jennings et al. (2009) analyze these processes and show that transmission of political values within a family are stronger when these values are salient in the broader political context. Hence, when environmental issues are high in the political agenda there is a stronger transmission within families of political values and environmental concerns. Giugni and Grasso (2019) observe that two generations who came of age in periods of intense mobilization are more active on the streets than other generations.

Other studies show that social movements transform society more thoroughly, they influence not only young people who belong to those social movement generations but society as a whole (Amenta and Polletta, 2019; Rochon, 2000). In this vein, researchers argue that western societies have embraced postmaterialistic values (Inglehart, 1977). The idea is that social movements' influence reaches broader segments of society and transforms the political values across different generations. In this case, there are two implications for action repertoires and political 
values. In terms of action repertoire, it relates to the idea of a normalization of protest which means that protest is a frequent mode of political action used by more diverse social groups and increasingly building on professional social movement organizations (Tarrow, 2011 [1994]). When it comes to political attitudes, this would mean that social movements contribute to the diffusion of new political values in society and, therefore, generations are indistinguishable in terms of political attitudes. Thus, it requires to understand how specific age groups form preferences with regard to environmental issues and how these preferences evolve over time to understand the dynamics of public opinion and how generational change might affect the aggregate preferences of the public over time. Or, in other words, to understand whether age has become a new cleavage structuring environmental politics as a consequence of the rise of environmental issues. Previous accounts put little emphasis on this structural element (Kissau et al., 2012; Goldberg, 2016). For those reasons, it is of importance to study the impact of age and generations on environmental attitudes.

\section{Age and Pro-environmental Attitudes}

Existing research on the relationship between age, generations, and environmental attitudes provides rather inconsistent results. Age and generational effects are discussed in a large number of studies of public opinion (Franzen and Meyer, 2010), but are rarely the specific focus of research, usually featuring simply as control variables. Andor et al. (2018) show that in Germany age is related with concerns about climate change in a non-linear fashion with highest degrees of concern being found in middle age groups and relatively lower levels of concern among the youth and elderly survey respondents. Attitudes toward public spending for the environment conform more to the theoretical model as it is the oldest age categories that are least supportive of such policies. A similar trend with low levels of support for public spending for the environment among the elderly have been found in other contexts including Sweden or the USA (Carlsson and Johansson-Stenman, 2000; Johnson and Schwadel, 2019). Gray et al. (2019) focus on differences in attitudes between four generations and show that there is hardly any difference between them regarding their level of environmental concern and the actions they would be ready to take to protect the environment.

There is little research focusing specifically on age or generational effects on pro-environmental attitudes in Switzerland. Existing studies show that attitudes toward the environment are similar across age groups in Switzerland. For instance, Franzen and Vogl (2013) show that despite an increase in media attention to environmental issues since the 1990 s public opinion has on average moved very little in relation to these issues between 1993 and 2010. Furthermore, no effect of age was found regarding environmental concern and willingness to pay for the environment. Another study focusing on post-electoral survey data in 2007 has shown that environmental protection is the issue about which there was the highest level of agreement between age groups with issues such as same sex marriage or the intervention of the state in the economy being much more divisive along generational lines (Kissau et al., 2012). Beiser-McGrath and
Huber (2018) show that preferences of Swiss respondents are much more closely associated with psychological rather than sociodemographic factors. Similarly, in a recent survey of public opinion on how the covid-pandemic might affect the environment, all age generations held similar opinions with clear majorities believing that the economy will be given priority over the environment in the long run (Monsch et al., 2020).

All in all, existing research does not show compelling evidence for the existence of systematic age or generational gaps in environmental concerns and policy preferences in Western democracies. One of the limitations of the current literature is that it mostly relies on cross-sectional data (see however, Johnson and Schwadel, 2019) and thus does not address the issue of how generations might change over time or how specific events might moderate the effect of age on preference. Also, no study, to the best of our knowledge, focused specifically on very young individuals and there is a risk of overseeing some large age differences that would be visible only among youngest generations.

\section{Environmentalism: Youth, Generational, or Social Change}

In the empirical part of our study, we examine generational differences in environmental protest participation and proenvironmental attitudes. First, regarding protest action repertoires, the literature on biographical availability suggests that we should expect a gap in relation to the participation of various age groups in protest events associated with the environmental movement with young adults making up the bulk of protesters. There are, however, reasons to believe that, given the long history of activism around environmental issues in Switzerland, members of older age groups (i.e., individuals of the environmental movement generations) also joined the movement, which revived some of the topics that were on the agenda of former movements. Hence, we examine the composition of the climate strike movement in terms of generations. We expect to observe an encompassing movement bringing different generations to the streets.

In the second part, we compare pro-environmental attitudes of different generations in 2017 and over time. Here, we consider two mechanisms of change over time. The first postulates that, independent of the age of the individual, the broader political context shapes political attitudes and behaviors. Hence, not only young people who come of age during a period of intense environmental mobilization adopt environmental attitudes but, to some extent, all citizens do. This means that all generations will be more preoccupied by the environment over time. In this case, we should observe an upward trend in environmental preferences across all generations. The second relates to generational change, we postulate that being socialized in a period of intense environmental mobilizations forms stable predispositions toward the environment that translate into specific attitudes and actions. If this is the case, the share of citizens who prioritize the environment should remain stable over time within a specific generation. In addition, we should observe variations between generations socialized in more intense 
periods of environmental mobilization, namely those coming of age around 1973 (the occupation of Kaiseraugst) and around 1986 (the Chernobyl accident). From that perspective, the greater concern for environmental issues among younger individuals would be linked to the fact that they grew up in contexts in which environmental issues became more salient. In this case, we anticipate a higher concern for environmental issues among generations of youth who experienced environmental movements in their formative years.

\section{Environmental Movements and Climate Strike in Switzerland}

One of the key features of the environmental movement is its success. As Touraine argues, major social transformations in the post-industrial society are associated with this movement (cited in Rootes, 2004; Giugni and Grasso, 2015). Although it is difficult to assess social movement outcomes, Rucht (1999) argues that the success of the environmental movement can be evaluated in relation to four elements. First, the movement grew importantly with more sympathizers and more resources available. It also consolidated, in part thanks to institutionalization with the creation of Green parties and many large environmental organizations that collaborate with the state. Giugni and Grasso (2015) argue that the institutionalization is a key feature of the movement. Second, the movement is an important agenda setter. Environmental issues are not only high in the political agenda, but also in citizens' minds and preoccupations. This is its third impact, the environmental movement transformed citizens' political attitudes and behaviors. Lastly, it contributed to the rise of a new economic sector and to new technologies. In relation to all these elements, the ecological movement has contributed, at least to some extent, to social changes. It reached broad segments of the population through the creation of environmental organizations, including green parties, and contributed to the diffusion of environmental attitudes in the population. This latter point is most important for us here and we will examine in the empirical section to what extent this claim is true among the Swiss population.

\section{Environmental Protest Waves in Switzerland}

The Swiss environmental movement is amongst the strongest in Europe, it benefits from a large anchorage in society with many formal organizations and broad membership (van der Heijden et al., 1992). The expansion and diversification of social movements are often associated with protest waves. Although the Swiss movement is less contentious than the German one (van der Heijden et al., 1992), several important protest waves shaped the movement and contributed to its expansion. Figure 1 presents protest events associated with the ecological and antinuclear movements in Switzerland between 1975 and 2011. ${ }^{5}$

${ }^{5}$ The early period from 1975 until 1995 is drawn from Giugni (2004) and for the years 1996-2011 we used data collected by Hutter (2014). Both datasets are collected following the same method, protest events are identified in the Monday edition of the NZZ (see Hutter and Giugni, 2009 for more information).

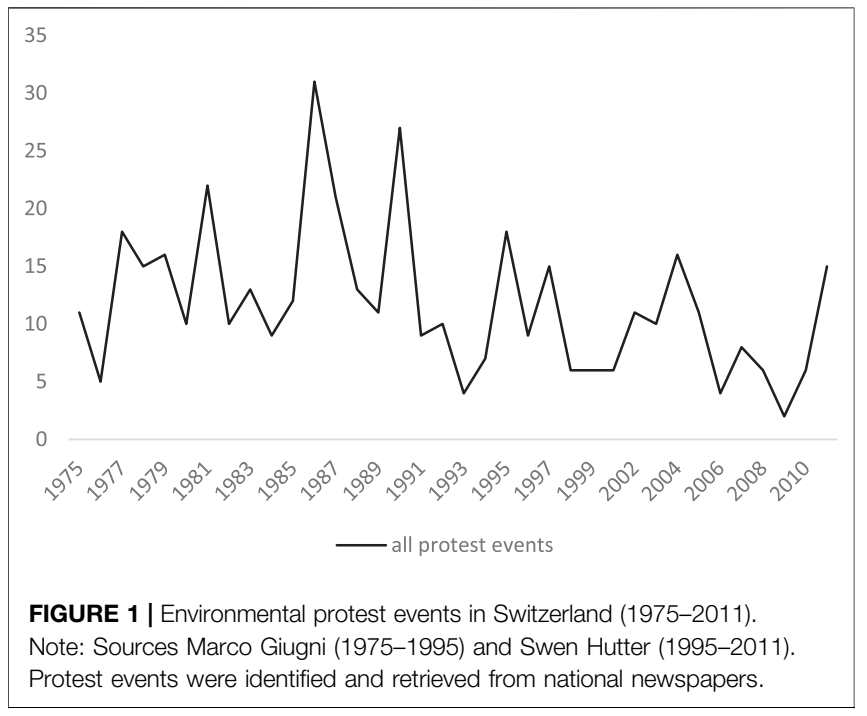

In Figure 1, we observe a first period of environmental mobilization in the period 1977-1981. This relates to and follows the occupation of Kaiseraugst to oppose the project to construct a nuclear plant on that site (Giugni, 2019). ${ }^{6}$ A first protest took place in 1973 and, then, in 1975 activists occupied the site for ten weeks. The Federal Council abandoned the project in 1988. Another intense period of mobilization appears during the period 1985-1991, with a clear peak in 1986 when 31 protest events took place. This peak is associated with national and international events that triggered protest. At the national level, a chemical accident in $\mathrm{Basel}^{7}$ and, at the international level, the Chernobyl accident. ${ }^{8}$ In 1990 , the Swiss people voted on a popular initiative demanding to stop constructing nuclear plants. Activists who campaigned on this issue also organized protest events to gain visibility in the media for anti-nuclear and ecological arguments.

Later, during the 1990s and 2000s, the environmental protest scene is more quiet. In the 1990s, the ecological movement mobilized around two issues: the death of forest and acid rain. In 2004, ecologists mobilized against chemical waste dump and GM food experiments in Swiss universities. There is again a peak in 2011 with the anti-nuclear mobilization that followed the Fukushima disaster. Antinuclear protesters gather every year in Beznau (a nuclear plant in central Switzerland) calling for the closure of one of the oldest nuclear plants in Europe still in operation. In 2011, the movement mobilized 20,000 protesters as well as numerous ecological organizations and political parties, the highest mobilization since 1986 .

${ }^{6}$ (see Giugni, 2019 for detailed accounts of ecological and antinuclear protest events).

${ }^{7}$ Toxic agrochemicals were dropped in the Rhine River following a fire in a chemical industry plant (Sandoz chemical spill).

${ }^{8}$ Following the Chernobyl accident, in 1986, 30'000 people marched to Gösgen nuclear plant. 
In 2019, youth have initiated the climate strike movement. For citizens who are young, this movement represents the first opportunity to engage in environmental protest events. The climate strike movement famously initiated in Sweden when Greta Thunberg sat in front of the Swedish parliament to call for strong action on climate change. In Switzerland, the beginnings can be traced back to the first action that gathered about 500 climate strikers, most of whom were school students in Zürich on December 14, 2018. A week later, the strike gathered around 4,000 participants across three Swiss cities (Basel, Bern, and Zürich). It quickly became a national movement and climate strikes were organized in sixteen cities and towns on January 18, 2019. Throughout 2019 and until March 2020 events were organized on at least eighteen occasions in a total of about 30 different cities across the country. ${ }^{9}$ Most of the events planned in the spring of 2020 had to be canceled due to the Covid-19 pandemic and the limitations for public gatherings that were decided by the Swiss government. However, the movement remains mobilized despite the strict measures in place, as the occupation of the square in front of the Federal Palace during the fall 2020 parliamentary session demonstrated.

Environmental activism has been present in Switzerland for decades; previous generations took to the streets and used protest events to express their environmental concerns. Opportunities for environmental sensibilization, thus, abound since at least half a century.

\section{Environmental Movement Generations in Switzerland} Neil Caren et al. (2011) refer to the Americans who came of age during the mobilizations of the 1960 s and 1970 s as the social movement generation. Other studies working on different countries also identified this generation as the most active in terms of protest participation (Giugni and Grasso, 2019). In this paper, we seek to construct political generations related to a specific social movement, namely the environmental one. There are different ways to group individuals in terms of cohorts (people born in specific years) or generations (people born in longer periods that experience historical changes in society). In this paper, we construct three environmental movement generations that correspond to the individuals who were young during periods of intense political mobilization around environmental issues. Previous work identified the period that range from 15 to 25 years old as the impressionable years-political events have a more lasting impact on individuals' political preferences, they shape how they view subsequent political events (Bartels and Jackman, 2014; Grasso, 2014). We consider that the formative years cover the premarital period-the average age of marriage in 1973 was 27 for men and 25 for women (Rosillion, 2008). Hence, we include all persons who were aged between 16 and 28 years old at the peak of the protest wave. Following this procedure, we constructed the Kaiseraugst generation around the 1973 protest wave and the Chernobyl generation around

\footnotetext{
${ }^{9}$ These estimations are based on the information provided on the website of the movement itself: https://de.climatestrike.ch/wiki/Klimastreik. They are likely conservative as, according to the media, at least 170 single climate strike events took place in 60 different cities in 2019 alone (see e.g. Le Nouvelliste, 26.11.2019).
}

the 1986 protest wave. We compare them to an older generation including all those who were born during the war (WWII) and the pre-war period, as well as to a younger generation of people born in the 1970s and early 1980s. The younger generation overlaps between generations XY depending on how the age range is defined, however the cut off year for generation X and Y is set around 1977/1978 (Jorgensen, 2003). Table 1 presents in detail birth years included in the different generations. Lastly, we consider the Climate Strike generation-those individuals who were young during the protest events organized by the Fridays for Future movement in 2019.

\section{DATA AND METHOD}

For this study, we use original Climate Strike data (CS) and the Swiss Household Panel (SHP). The CS data allows us to examine the generational composition of the climate strike demonstrations. Whereas, the SHP, offers a longitudinal overview of environmental attitudes of different generations among the general population.

\section{Climate Strike Survey and Swiss Household Panel}

The climate strike data were collected in the framework of a large coalition of research teams across different countries (Wahlström et al., 2019; de Moor et al., 2020). The Swiss data were collected by the leading author during three demonstrations: two that took place on March 15th, 2019, in Geneva and in Lausanne, and one in Bern on September 28th, 2019. During each of these three demonstrations a team of students and researchers distributed 1,000 flyers to access an online survey about their current participation in the demonstration, their political attitudes, their political behaviors, and socio-demographic control variables. The participants were selected using a procedure to randomize the selection and to construct a representative sample of participants in the demonstration (Walgrave and Verhulst, 2011). As we handed out flyers to access the online survey, we asked one in five potential survey respondent to fill a small questionnaire to assess the sociodemographic profile, political attitudes, and relation to protest of the people who participate in the different demonstrations. This allows us to analyze the composition of the event and, thus, to gain knowledge about the population from which the sample is drawn. We compare survey respondents to demonstrators in terms of sociodemographic profiles (sex, age, and level of education), political attitudes (political interest), and relation to protest (prior participation in demonstrations, timing of the decision to participate in this demonstration). In so doing, we can assess how representative the sample is. Comparing survey respondents to street demonstrators, we identified one systematic bias, those demonstrators who are interested in politics are more likely to answer the online survey than participants invited to fill in the online survey who are not interested in politics. The response rate for the three demonstrations range from 15 percent in Geneva to 29 percent in Bern and the total sample includes 608 respondents (see Table A1). 
TABLE 1 | Generations, protest year, and birth years.

\begin{tabular}{|c|c|c|c|c|}
\hline Generations & Peak of protest & Age during protest years & Birth years & Age in 2019 \\
\hline Prewar/war & - & - & $<1945$ & $>74$ \\
\hline Kaiseraugst & 1973 & $16-28$ & $1945-1957$ & 62 to 74 \\
\hline Chernobyl & 1986 & $16-28$ & 1958-1970 & 61 to 49 \\
\hline$X$ and $Y$ & - & - & 1971-1990 & 48 to 29 \\
\hline Climate strike & 2019 & $16-28$ & 2003-1991 & 28 to 16 \\
\hline
\end{tabular}

Regarding the Swiss Household Panel, we have fourteen available waves over a period of eighteen years (1999-2017). In total, we have three samples as the SHP added two refreshment samples to their original sample of 1999 in 2004 and 2013 respectively. As for every panel study, attrition is one of the biggest sources for bias. However, existing analyses have shown that attrition is mostly random and estimate the nonresponse bias as mild (Voorpostel, 2009). Nevertheless, non-respondents tend to be younger, male, lower educated, single, with less interest in politics and civic engagement, as well as equipped with lower levels of political and social trust. In an attempt to control for attrition bias, we conducted all analyses twice: once with standardized longitudinal weights and once without weights. We include all individuals in our analyses as soon as they turn sixteen and integrate them in the analysis. ${ }^{10}$ For example, an individual who is born in 1994 is included in the analysis from 2010 onwards. This adds up to a sample of 12,931 respondents in 1999 and 12,164 respondents in 2017. Individuals are included individually and not by groups and the results cannot be interpreted as within individual changes over time but as changes between generations over time.

\section{Dependent Variable: Pro-environmental Attitudes}

Our dependent variable are opinions regarding the prioritization of the environment over the economy. When working on environmental attitudes, it is important to ask what it means to be concerned by environmental issues. Working on the idea that we are now in a post political era, some argue that the issue of climate change is a consensual one. Almost everyone admits that this is one of the most pressing issue of our time, yet the issue is presented in apocalyptic terms that prevent any action from being taken (Swyngedouw, 2010). The environment is considered as valence issue, that is an issue on which a vast majority of people have the same position but give different priority to that issue. Hence, we need to devise measures of environmental concern that capture support for the environment as well as the cost of this action. We argue that environmental concern can be measured when real choices are offered as for example to prioritize the environment over the economy. This means that people are ready to give up growth and eventually some of their material wellbeing to promote an alternative relation to the

${ }^{10}$ At fourteen, respondents fill out for the first time the individual questionnaires including all the variables of interest here. environment-that is not one of extraction and exploitation. In fact, the climate strikers called for "system change and not climate change" in the framework of the protest events that we analyze.

In the SHP, we have a question measuring this tradeoff. The question asks: "Are you in favor of Switzerland being more concerned with protection of the environment than with economic growth, or in favor of Switzerland being more concerned with economic growth than with protection of the environment?"11 It is measured on a three-state interval variable: "in favor of stronger protection of the environment," "neither," "in favor of stronger economic growth." We dichotomize the variable opposing those who say they support stronger environmental protection to all others (those who support neither and those who support stronger economic growth).

\section{Independent Variable: Age and Generations} To study the relation between generations and proenvironmental attitudes, we construct five generations that correspond to the generations identified in relation to environmental protest waves in Switzerland (see Table 1). For the CS data, we consider the age of the respondent in 2019 whereas, for the SHP, we consider the age in 2017 (the last available wave of the panel with the environmental question). When constructing these five generations, we observe that the prewar/war generation includes very few respondents in the CS data (see Table A2). Hence, we do not consider this generation in the analyses of the CS.

\section{RESULTS}

\section{Climate Strikers: Youth or Cross-Age Call for Action?}

During the year 2019, climate strikers took to the streets to express their worries and their dissatisfaction with how the government is handling the issue of climate change. Many observers around the world qualified this protest wave as a "youth movement," in fact many school pupils and students engaged in these actions. However, in the Swiss case, climate

${ }^{11}$ Original versions of the question in German, French, and Italian are available on the SHP website: https://forscenter.ch/projects/swiss-household-panel/. The question was asked in all years between 1999 and 2009 and then in 2011, 2014, and 2017. The question will also be asked in the 2020/21 version of the survey that is still in the field at the time of writing this manuscript. 


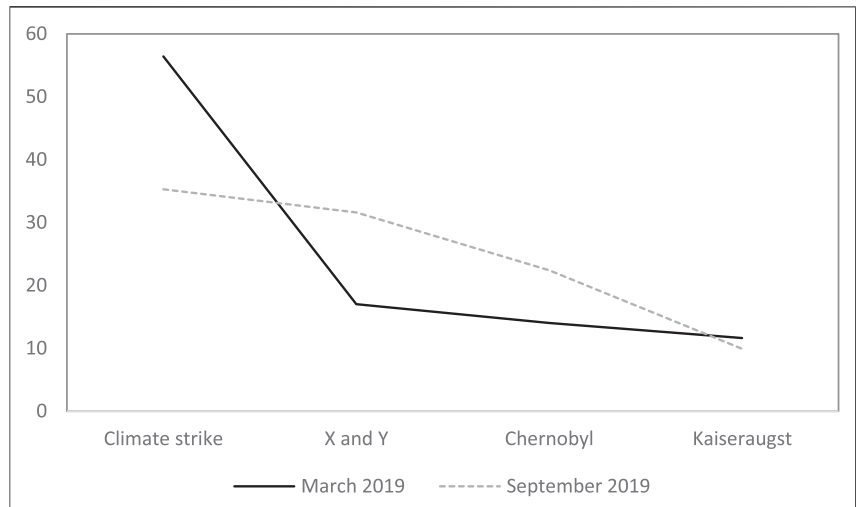

FIGURE 2 | Generations among climate strikers who took to the streets in March 2019 (Lausanne and Geneva) and September 2019 (Bern). Note: We run a chi-square test to compare respondents who belong to the different generations in March and September 2019. We find that differences in the share of respondents from the Climate strike, the $X$ and $Y$, as well as the Chernobyl generations reach conventional levels of statistical significance. There are less members of the Climate generations in September and more members of the generations $X / Y$ and Chernobyl. The Kaisergaust is equally present in protest events that took place in March and in September 2019.

strikers mobilized across age categories. Figure 2 shows that the climate strike generation constituted an important share of demonstrators in the early phase of the protest (56.4 percent), whereas in September 2019 they represent only a third of all demonstrators ( 35.3 percent). By the fall, the movement mobilized far beyond schools and universities including an increasing share of people from older generations. In particular, the share of demonstrators who belong to the generation $\mathrm{X}$ and $\mathrm{Y}$ increased (from 17.0 to 31.6 percent). Regarding the two environmental generations, we observe two distinct trajectories. While the share of demonstrators who belong to the Chernobyl generations increased (from 14.0 to 22.4 percent), the share of demonstrators who belong to the Kaiseraugst generation remains stable over time (11.6 vs. 9.9 percent). We also examined the age distribution and we observe a peak among the very young participants, less than 20 years old (figure presented in Figure A1). Climate strike demonstrators aged 17 years old display the highest percentage with 7.4 percent of the overall sample. Similarly, 18 and 19 years old have slightly higher percentages than age groups of the climate strike generation (respectively 6.3 and 6.6 percent). In the other three generations, we do not observe any clear pattern. Overall, we find that all age categories are present within each generation.

Figure 2 shows that the climate strikers are not all young. In the fall, the climate strikers who took to the street include a crossgenerational coalition of citizens. Interestingly, the environmental generations (Kaiseraugst and Chernobyl) represent a small share of the climate strikers. They add up to a quarter of all demonstrators in March and about a third in September 2019. Whereas, the generation X and Y, which did not experience any major environmental protest wave when they were young, are as active as the younger (climate strike) generation. This shows that far from being a youth movement, the climate strike movement is an encompassing movement. It brought different generations to the streets of Swiss cities in 2019. In spite of the presence of different generations on the streets, these findings show little support for the idea that the environmental generation remain more active in protest over time. We find that the generation $\mathrm{X}$ and $\mathrm{Y}$ who did not experience environmental protest waves when they were young joined the climate strike generation on the streets of Swiss cities in 2019. Our findings also show that members of the Kaiseraugst generation were equally present on the streets at the onset of the movement in March 2019 and in the fall. Providing some support for the idea that early socialization in protest might contribute to future protest and more specifically for abeyance theory (Taylor, 1989)-individuals who belong to the Kaiseraugst generation might have remained active in environmental organizations and, therefore, can more rapidly be mobilized for protest events in line with this political engagement. Let us now move to the dynamic perspective and seek to understand how change happens, through period effects when the whole population moves up or through generational effects.

\section{Changes in Environmental Attitudes in the Swiss Population}

Descriptive analyses of environmental attitudes among different generations provide us with some useful hints regarding how changes in environmental attitudes take place. Figure 3 displays the share of respondents who favor the environment over the economy for the five generations over time. In line with current recommendations (see e.g., Julious, 2004), we present these estimates with $84 \%$ confidence intervals. The $84 \%$ confidence intervals allow to assess visually whether differences in the means across groups (or in that case also across years) are significant at $p<0.05$. If the confidence intervals do not overlap, the difference between the means is significant. The picture that emerges from Figure $\mathbf{3}$ is quite telling regarding differences in proenvironmental attitudes be they related to age, generation, or period. Overall, two trends emerge from this picture. First, at any given point in time, younger generations are more likely to be on average more favorable to the environment than older generations. While adjacent generations do not strongly differ from each other, significant differences exist between more removed ones.

Although differences across generations are relatively small, the overall picture shows greater environmental concern among younger generations. Most importantly, it appears that generations evolve in parallel and seem to respond to more general trends in society toward an increase in environmental concern. This lends support to the idea that the whole society is holding more pro-environmental attitudes over time. For instance, in all generations, pro-environmental attitudes have increased during the 2003 to 2007 period as well as between 2009 and 2019. These results show that environmental concerns are related to the broader political context and increase over time across generations.

In order to examine the idea that change is specifically connected to generations who came of age in periods of intense environmental 


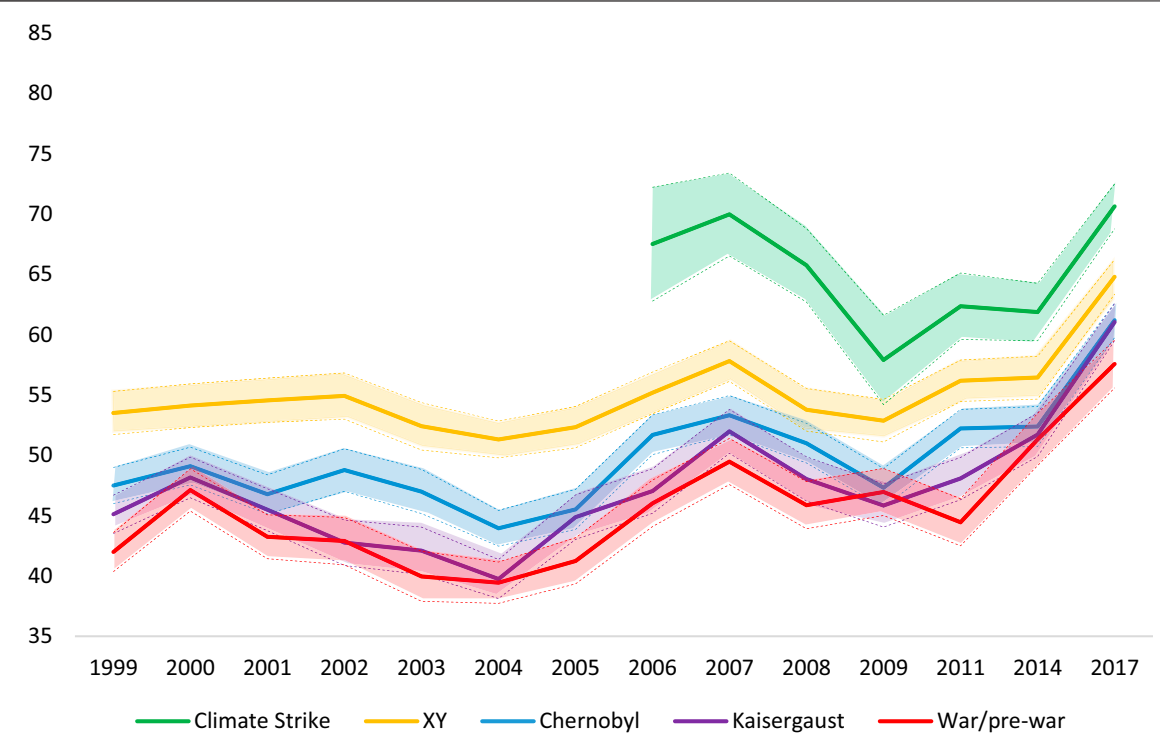

FIGURE 3 | Share of respondents who believe that the environment is more important than the economy in different generations and over time.

protest, we zoom on these generations. The Kaiseraugst generation appears to be closely aligned with the pre-/war generation. We do not observe a major gap between these two generations when it comes to their environmental attitudes. In fact, the environmental preferences of these two generations do not differ from a statistical perspective as can be seen in Figure 3 thanks to the confidence intervals. However, when we compare the pre-/war generation to the Chernobyl generation the gap appears to increase. The environmental preferences of the Chernobyl generation do not differ from those of the Kaiseraugst generation from a statistical point of view. Yet, the environmental preferences of the Chernobyl generation are significantly different from those of the pre-war and war generation. This relates to the idea that there are no major gaps between older and younger generations that cohabit within a given society since intermediary generations create bridges (Mannheim, 1970). The Kaiseraugst generation paved the way for the Chernobyl generation, which pushed up more significantly the share of citizens who hold pro-environmental attitudes and differs more from older generations. This is confirmed when we compare the younger generations to older ones. Statistically significant difference appears when we compare the climate strike and the $\mathrm{X}$ and $\mathrm{Y}$ generations to the Kaiseraugst and Prewar/war generations. However, only the climate strike generations systematically differs from the Chernobyl generation in terms of environmental preferences.

\section{DISCUSSION}

Previous research has shown that youth are particularly likely to participate in social movements. It is also clear by analyzing the development of the climate strike movement in Switzerland that it has been initiated by young individuals, mostly school students, echoing what has happened in other countries. This central role of youth in initiating the movement is actually common for the emergence of many social movements, however often it is more associated with university students (e.g., May 68 movement, the Indignados, Black Lives Matter). What is specific about the climate strike movement is that it was initiated in schools thus by individuals who by and large did not have citizenship rights due to their very young age. Based on the media accounts of the climate strike movement we would expect that protesters were almost exclusively very young. However, given the long history of environmental politics in Switzerland, we anticipated that members of older generations who possibly participated in previous waves of environmental protest, would join the climate strike movement. Indeed, we observe that older citizens drawn from both their parents and their grandparents' generations have joined young people on the streets in the fall of 2019. In September 2019, youth represent only a third of the 100,000 protesters who took to the streets.

Regarding environmental attitudes, it is of course tempting to think that the emergence of the climate strike movement reflects a large gap in environmental preferences and concerns across generations. After all, if pupils who were in school took the street in 2018/19 and those who were in a similar situation a decade before did not, it must mean that they hold different preferences. The current youth generation has indeed been exposed to more information about climate change than any other and there are reasons to believe that it has a better understanding of this issue than its predecessors at the same age. In addition, one could argue that this generation is more likely than others to be conscious of the fact that it will be dramatically affected by climate change. The prevalence of public discourse about climate make it clear for youth that they will be personally affected, which might be less obvious for generations whose remaining life expectancy is shorter. However, the information to which the current youth generation is exposed to is actually not specific to them and other generations might be affected by this information as well. Also, given the already visible consequences of climate change nowadays it is not obvious that 
any generation might feel potentially unaffected by it. It is therefore unlikely that there is an abyssal gap in the environmental policy preferences between generations.

We show that the current youth generation holds more proenvironmental attitudes than its predecessors. Moreover, we show that the share of pro-environmental preferences has been increasing from one generation to the other, given that the attention brought to environmental issues has been growing since the 1990s at least (Franzen and Vogl, 2013). Hence, we observe an overall greening that spans across age categories and we do not find empirical support for the idea that some generations, given their exposure to social movements' environmental ideas during their formative years, are more likely to hold pro-environmental attitudes.

\section{CONCLUSION}

We started with the commonly held belief that the climate strike is a youth movement and that young people hold more pro-environmental attitudes. Using protest event data, climate strike survey, and longitudinal data, we deconstruct these ideas. We show that climate strikers who took part in the national demonstration in Bern were drawn from all generations. In addition, the Swiss Household panel data show that the gap in pro-environmental attitudes between youth and older respondents is only limited. Looking at the Swiss population as a whole it appears that youth have more pro-environmental preferences than older generations. However, each generation has been more proenvironmental than its predecessor has. This already lends support to the idea that generations live together and that ideas travel across generations. In fact, our analyses of longitudinal data shows that different generations tend to adopt more pro-environmental attitudes at the same time. Thus, pointing to a period effect. In addition, we find limited evidence that the generations coming of age in periods of intense environmental mobilization hold more proenvironmental attitudes than other generations.

In this paper, we examined generational differences in protest participation and pro-environmental attitudes. First, we situated the climate strike in a broader understanding of the environmental movement in Switzerland. Protest event data shows that several protest waves took place over the period 1975-2015. This is important because it means that previous generations mobilized to defend the environment when they were young and this might have multiple long-term consequences. First, it might durably shape the environmental attitudes of those who participated in these protest waves but also of others who were coming of age at the time of this event. This corresponds to the idea of generations socialized in periods of intense social change and durably marked by this experience. Second, the environmental ideas at the core of these mobilizations might contribute to broader social change. The movement results in the creation of institutions (both political parties and environmental organizations) that seek to influence public opinion through different means. They might act directly on decision-making processes within political institutions but they also seek to gain media attention. Overall, this means that environmental attitudes may travel in society through multiple routes following different protest waves.
Building on the information about environmental protest waves in Switzerland, we identified generations of young people that came of age during intense periods of environmental mobilization. Those who were young during the Kaiseraugst occupation, those who were young when the Rhine River pollution and Chernobyl accident happened, and those who were young as the climate strike demonstrations took to the streets. Our longitudinal analyses show that the climate strike generation stand out and hold more pro-environmental attitudes than any other generation. However, they are still young at the time of our study so we cannot say whether this relates to youth or to a specific socialization of this young generation that will hold throughout their life. When we turn to the other two environmental generations, we find that the Kaiseraugst and the Chernobyl generations do not stand out in terms of environmental preferences. Instead, they appear to be part of a more general trend in society-the diffusion of proenvironmental attitudes across all age groups and generations.

From a policy perspective our results are mixed. On the one hand, they show that there are no clear generational cleavage on environmental issues in Switzerland. This suggests that there is room for finding broad coalitions that encompass all generations to protect the environment. On the other, these results also make it clear that overall changes in the opinions of citizens are relatively slow. While the share of environment supporters has increased across all generations over the last decade, the pace of this change might be seen as insufficient to address the urgent environmental challenges linked with climate change.

Finally, it is important to note some of the limits of our research. We are not able to identify respondents who participated in the environmental mobilization in the past and to compare their environmental attitudes to those who did not participate in the same generation or in other generations. This means that we are testing the idea that generations socialized in intense periods of mobilization with data that make the test difficult to pass. In addition, we are not able to identify the external effects that might account for the period effect that we identify. Important events in the environmental movement are the 2009 mobilization around the COP in Copenhagen. This event raised high expectations and triggered a broad disillusion after its failure. However, we do not observe important shifts in pro-environmental attitudes around this event. Similarly, in 2015, the COP in Paris was a highly mediatized event. Yet, our data do not allow following the ups-and-downs in public opinion, instead we measure aggregate changes within generations. One of the avenues for future research is to try to disentangle the age, cohort as well as period effects, which could be achieved by modeling environmental attitudes at the individual level.

\section{DATA AVAILABILITY STATEMENT}

The data analyzed in this study is subject to the following licenses/ restrictions: The paper builds on three datasets, the protest event datasets are available here (https://poldem.eui.eu/), the climate strike data is only available for the national teams who took part in the data collection for the time being, the Swiss Household Panel data is 
available for researchers here (https://forsbase.unil.ch/project/studypublic-overview/16970/0/). Requests to access these datasets should be directed to https://poldem.eui.eu/ and https://forsbase.unil.ch/ project/study-public-overview/16970/0/.

\section{ETHICS STATEMENT}

Ethical review and approval was not required for the study on human participants in accordance with the local legislation and institutional requirements. Written informed consent from the participants' legal guardian/next of kin was not required to participate in this study in accordance with the national legislation and the institutional requirements.

\section{AUTHOR CONTRIBUTIONS}

All authors listed have made a substantial, direct, and intellectual contribution to the work and approved it for publication.

\section{REFERENCES}

Amenta, E., and Polletta, F. (2019). The Cultural Impacts of Social Movements. Annu. Rev. Sociol. 45 (1), 279-299. doi:10.1146/annurev-soc-073018-022342

Amnå, E., and Ekman, J. (2014). Standby Citizens: Diverse Faces of Political Passivity. Eur. Pol. Sci. Rev. 6 (2), 261-281. doi:10.1017/s175577391300009x

Andor, M. A., Schmidt, C. M., and Sommer, S. (2018). Climate Change, Population Ageing and Public Spending: Evidence on Individual Preferences. Ecol. Econ. 151, 173-183. doi:10.1016/j.ecolecon.2018.05.003

Bartels, L. M., and Jackman, S. (2014). A Generational Model of Political Learning. Elect. Stud. 33, 7-18. doi:10.1016/j.electstud.2013.06.004

Beiser-McGrath, L. F., and Huber, R. A. (2018). Assessing the Relative Importance of Psychological and Demographic Factors for Predicting Climate and Environmental Attitudes. Climatic Change 149 (3), 335-347. doi:10.1007/ s10584-018-2260-9

Caren, N., Ghoshal, R. A., and Ribas, V. (2011). A Social Movement Generation. Am. Sociol. Rev. 76 (1), 125-151. doi:10.1177/0003122410395369

Carlsson, F., and Johansson-Stenman, O. (2000). Willingness to Pay for Improved Air Quality in Sweden. Appl. Econ. 32 (6), 661-669. doi:10.1080/ 000368400322273

Corrigall-Brown, C. (2011). Patterns of Protest: Trajectories of Participation in Social Movements. Calif: Stanford University Press. doi:10.1515/9780804778190

Dahl, V., Amnå, E., Banaji, S., Landberg, M., Šerek, J., Ribeiro, N., et al. (2018). Apathy or Alienation? Political Passivity Among Youths across Eight European Union Countries. Eur. J. Develop. Psychol. 15 (3), 284-301. doi:10.1080/ 17405629.2017.1404985

de Moor, J., Uba, K., Wahlström, M., Wennerhag, M., and De Vydt, M. (2020). Protest for a Future II: Composition, Mobilization and Motives of the Participants in Fridays for Future Climate Protests on 20-27 September, 2019, in 19 Cities Around the World.

Earl, J., Maher, T. V., and Elliott, T. (2017). Youth, Activism, and Social Movements. Sociol. Compass 11 (4), e12465. doi:10.1111/soc4.12465

Franzen, A., and Meyer, R. (2010). Environmental Attitudes in Cross-National Perspective: A Multilevel Analysis of the ISSP 1993 and 2000. Eur. Sociol. Rev. 26 (2), 219-234. doi:10.1093/esr/jcp018

Franzen, A., and Vogl, D. (2013). Time Preferences and Environmental Concern. Int. J. Sociol. 43 (4), 39-62. doi:10.2753/ijs0020-7659430401

Giugni, M., and Grasso, M. (2019). Street Citizens: Protest Politics and Social Movement Activism in the Age of Globalization. Cambridge: Cambridge University Press. doi:10.1017/9781108693455

\section{FUNDING}

JL and JR thankfully acknowledge the support of the Leenaards Foundation (research project: Engagements civiques et politiques des seniors: se battre pour le climat pour bien vieillir?).

\section{ACKNOWLEDGMENTS}

A previous version of this research has been presented at the Annual Conference of the Swiss Political Science Association in Luzern in February 2020. We are grateful to the panel participants for their helpful comments. We would also like to thank the two reviewers who provided useful comments to improve this contribution. JL and JR thankfully acknowledge the support of the Leenaards Foundation (research project: Engagements civiques et politiques des seniors: se battre pour le climat pour bien vieillir ?). We are also grateful to Amédée Félix for excellent research assistance.

Giugni, M., and Grasso, M. T. (2015). Environmental Movements in Advanced Industrial Democracies: Heterogeneity, Transformation, and Institutionalization. Annu. Rev. Environ. Resour. 40, 337-361. doi:10.1146/ annurev-environ-102014-021327

Giugni, M. (2019). La Suisse dans la rue: Mouvements, Mobilisations, Manifestants. Lausanne: Presses polytechniques et universitaires romandes.

Giugni, M. (2004). Social Protest and Policy Change: Ecology, Antinuclear, and Peace Movements in Comparative Perspective. Lanham, MD: Rowman \& Littlefield.

Goldberg, A. C. (2016). The Impact of Cleavages on Swiss Voting Behaviour: A Modern Research Approach. Berlin, Germany: Springer.

Grasso, M. T. (2014). Age, Period and Cohort Analysis in a Comparative Context: Political Generations and Political Participation Repertoires in Western Europe. Elect. Stud. 33, 63-76. doi:10.1016/j.electstud.2013. 06.003

Gray, S. G., Raimi, K. T., Wilson, R., and Árvai, J. (2019). Will Millennials Save the World? the Effect of Age and Generational Differences on Environmental Concern. J. Environ. Manage. 242, 394-402. doi:10.1016/j.jenvman.2019.04.071

Henn, M., Weinstein, M., and Wring, D. (2002). A Generation Apart? Youth and Political Participation in Britain. The Br. J. Polit. Int. Relations 4 (2), 167-192. doi:10.1111/1467-856X.t01-1-00001

Hutter, S., and Giugni, M. (2009). Protest Politics in a Changing Political Context: Switzerland, 1975-2005. Swiss Polit. Sci. Rev. 15 (3), 427-461. doi:10.1002/j. 1662-6370.2009.tb00141.x

Hutter, S. (2014). Protesting Culture and Economics in Western Europe: New Cleavages in Left and Right Politics. Minneapolis: University of Minnesota Press. doi:10.5749/minnesota/9780816691180.001.0001

Inglehart, R. (1977). The Silent Revolution: Changing Values and Political Styles Among Western Publics. Princeton N.J.: Princeton University Press.

Jennings, M. K., Stoker, L., and Bowers, J. (2009). Politics across Generations: Family Transmission Reexamined. J. Polit. 71 (03), 782-799. doi:10.1017/ s0022381609090719

Johnson, E. W., and Schwadel, P. (2019). It Is Not a Cohort Thing: Interrogating the Relationship between Age, Cohort, and Support for the Environment. Environ. Behav. 51 (7), 879-901. doi:10.1177/0013916518780483

Jorgensen, B. (2003). Baby Boomers, Generation X and Generation Y?: policy implication for defence forces in the modern era. Foresight 5 (4), 41-49. doi:10. $1108 / 14636680310494753$

Julious, S. A. (2004). Using Confidence Intervals Around Individual Means to Assess Statistical Significance between Two Means. Pharmaceut. Statist. 3 (3), 217-222. doi:10.1002/pst.126 
Kissau, K., Lutz, G., and Rosset, J. (2012). Unequal Representation of Age Groups in Switzerland. Representation 48 (1), 63-81. doi:10.1080/00344893.2012. 653241

Mannheim, K. (1970). The Problem of Generations. Psychoanalytic Rev. 57 (3), $378-404$.

McAdam, D. (1986). Recruitment to High-Risk Activism: The Case of Freedom Summer. Am. J. Sociol. 92 (1), 64-90. doi:10.1086/228463

Milkman, R. (2017). A New Political Generation: Millennials and the Post2008 Wave of Protest. Am. Sociol. Rev. 82 (1), 1-31. doi:10.1177/ 0003122416681031

Monsch, G.-A., Ehrler, F., and Steinmetz, S. (2020). Politik, Grundrechte und Umweltsorgenwährend dem Lockdown. Available at: https://forscenter.ch/ projects/fors-covid-19-surveys/.

O'Toole, T. (2003). Engaging with Young People's Conceptions of the Political. Children's Geographies 1 (1), 71-90. doi:10.1080/14733280302179

Rochon, T. R. (2000). Culture Moves: Ideas, Activism, and Changing Values. Princeton, NJ: Princeton University Press.

Rootes, C. (2004). "Environmental Movements," in The Blackwell Companion to Social Movements. Editors D. A. Snow, S. A. Soule, and H. Kriesi (Oxford, United Kingdom: Blackwell), 608-640.

Rosillion, S. (2008). Mariages et divorces. Evolution selon quelques déterminants socio-démographiques. Genève: Office cantonal de la statistique (OCSTAT), Genève. Retrieved from https://www.ge.ch/statistique/tel/publications/2008/ analyses/communications/an-cs-2008-37.pdf (Accessed November 11, 2020).

Rucht, D. (1999). The Impact of Environmental Movements in Western Societies. How Soc. movements matter 10, 204-224.

Schussman, A., and Soule, S. A. (2005). Process and Protest: Accounting for Individual Protest Participation. Social Forces 84 (2), 1083-1108. doi:10.1353/ sof.2006.0034

Swyngedouw, E. (2010). Apocalypse Forever? Theory. Cult. Soc. 27 (2-3), 213-232. doi:10.1177/0263276409358728

Tarrow, S. (2011). Power in Movement: Social Movements and Contentious Politics. Vol. 3rd Ed. Cambridge: Cambridge University Press.
Tarrow, S. (1989). Democracy and Disorder: Social Conflict, Political Protest and Democracy in Italy, 1965-1975. New York: Oxford University Press.

Taylor, V. (1989). Social Movement Continuity: The Women's Movement in Abeyance. Am. Sociol. Rev. 54 (5), 761-775. doi:10.2307/2117752

van der Heijden, A., Koopmans, R., and Giugni, M. (1992). "The West European environmental movement," in The Green movement worldwide. Editors M. Finger (Greenwich: JAI Press), 1-40.

Verba, S., Schlozman, K. L., and Brady, H. E. (1995). Voice and Equality: Civic Voluntarism in American Politics. Cambridge, Massachusetts: Harvard University Press.

Voorpostel, M. (2009). Attrition in the Swiss Household Panel by Demographic Characteristics and Levels of Social Involvement.

Wahlström, M., Sommer, M., Kocyba, P., de Vydt, M., De Moor, J., Davies, S., et al. (2019). Protest for a Future: Composition, Mobilization and Motives of the Participants in Fridays for Future Climate Protests on 15 March, 2019 in 13 European Cities.

Walgrave, S., and Verhulst, J. (2011). Selection and Response Bias in Protest Surveys. Mobilization: Int. Q. 16 (2), 203-222. doi:10.17813/maiq.16.2. j475m8627u4u8177

Wiltfang, G. L., and McAdam, D. (1991). The Costs and Risks of Social Activism: A Study of Sanctuary Movement Activism. Soc. Forces 69 (4), 987-1010. doi:10. 1093/sf/69.4.987

Conflict of Interest: The authors declare that the research was conducted in the absence of any commercial or financial relationships that could be construed as a potential conflict of interest.

Copyright (C) 2021 Lorenzini, Monsch and Rosset. This is an open-access article distributed under the terms of the Creative Commons Attribution License (CC BY). The use, distribution or reproduction in other forums is permitted, provided the original author(s) and the copyright owner(s) are credited and that the original publication in this journal is cited, in accordance with accepted academic practice. No use, distribution or reproduction is permitted which does not comply with these terms. 


\section{APPENDIX}

TABLE A1 | Climate strike survey information.

\begin{tabular}{|c|c|c|c|c|c|}
\hline City & Date & $\begin{array}{l}\text { Estimated number } \\
\text { of participants }\end{array}$ & Distributed flyers & $\mathbf{N}$ & $\begin{array}{c}\text { Response rate } \\
(\%)\end{array}$ \\
\hline Lausanne & 15.03 .2019 & $12,000-15,000$ & 1000 & 183 & 18 \\
\hline Geneva & 15.03 .2019 & $5,000-6,000$ & 1000 & 154 & 15 \\
\hline
\end{tabular}

TABLE A2 | Percentage of respondent in each generation (CS and SHP) and in the Swiss population (Swiss Federal Office for Statistics-OFS).

\begin{tabular}{|c|c|c|c|c|c|}
\hline \multirow[b]{2}{*}{ Generations } & \multicolumn{3}{|c|}{ Climate strike } & \multirow{2}{*}{$\frac{\text { SHP }}{\text { Switzerland }}$} & \multirow{2}{*}{$\frac{\text { OFS }}{\text { Switzerland }}$} \\
\hline & Geneva & Lausanne & Bern & & \\
\hline Climate strike & 52.3 & 59.9 & 35.3 & 19.7 & 15.1 \\
\hline$X$ and $Y$ & 19.6 & 14.8 & 31.6 & 24.8 & 28.3 \\
\hline Chernobyl & 13.1 & 14.8 & 22.4 & 24.4 & 19.2 \\
\hline Kaiseraugst & 13.7 & 9.9 & 9.9 & 20.4 & 13.3 \\
\hline Prewar/war & 1.3 & 0.6 & 0.7 & 10.7 & 9.2 \\
\hline $\mathrm{N}$ & 153 & 182 & 272 & $12,003^{\mathbf{a}}$ & $8,419,550^{\mathbf{b}}$ \\
\hline
\end{tabular}

${ }^{a}$ The percentages presented here and the N are calculated on the 2017 SPH wave.

${ }^{b}$ The percentages do not add up to 100 percent because the table does not present

Swiss residents who are younger than 16 years old (14.9 percent of the population).

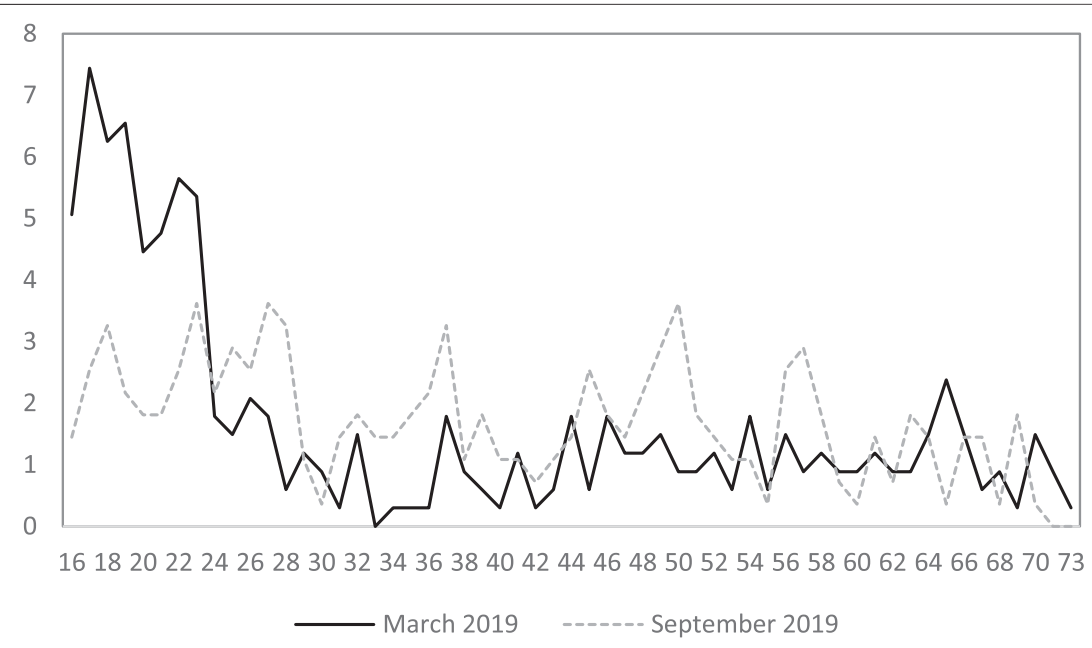

FIGURE A1 | Age of climate strikers. 